\title{
Process Capability Analysis in a Polypropylene Bag Manufacturing Company
}

\section{*ODEYINKA, OF; OGUNWOLU, FO; POPOOLA, OP; OYEDOKUN, TO}

\author{
Department of Systems Engineering, University of Lagos, Akoka, Lagos, Nigeria \\ *Corresponding Author Email: oodeyinka@unilag.edu.ng; Other Authors Email:fogunwolu@unilag.edu.ng, ,opopoola@unilag.edu.ng , \\ topeoyedokun@bagco-ng.com
}

\begin{abstract}
Process capability analysis combines statistical tools and control charts with good engineering judgment to interpret and analyze the data representing a process. This work analyzes the process capability of a polypropylene bag producing company. The case study organization uses two plants for production and data was collected over a period of nine months for this study. Analysis showed that the output spread of plant 1 was greater than the specification interval spread which implies poor capability. There are non-conforming parts below the Lower Specification Limit (LSL: 500,000 metres) and above the Upper Specification Limit (USL: 600,000 metres) and that the output requires improvement. Similarly, the capability analysis of plant 2 shows that the overall output spread is greater than the specification interval spread (poor capability). The output centre in the specification and overall interval are vertically aligned, thus specifying that the output from plant 2 is also process centered and requires improvement. Recommendations were made to improve the outputs from each production plant.
\end{abstract}

DOI: https://dx.doi.org/10.4314/jasem.v25i8.30

Copyright: Copyright $(\odot 2021$ Odeyinka et al. This is an open access article distributed under the Creative Commons Attribution License (CCL), which permits unrestricted use, distribution, and reproduction in any medium, provided the original work is properly cited.

Dates: Received: 10 May 2021; Revised: 28 June 2021; Accepted: 01 July 2021

Keywords: Capability Index, Process Capability, Quality Control, Specification Limits

All processes have inherent statistical variability which can be evaluated by statistical methods. The analyses of manufacturing processes play a vital role in quality control and continuous improvement (Shi et al., 2016). These analyses use indices such as the process capability and potential process capability index as quantitative measures of assessing whether a production process under study is capable of delivering products that meet the required specifications (Dharmasena and Zeephongsekul, 2016). These indices are still widely used by process engineers despite a growing recognition of their limitations. The process capability index $(\mathrm{Cp})$ index remains the most popular of the indices (Lupo, 2015). Process capability analysis combines statistical tools and control charts with good engineering judgment to interpret and analyze the data representing a process (Wooluru, et al. 2014; Young-Vazquez et al., 2021). Process Capability refers to the evaluation of how well a process meets specifications or the ability of the process to produce parts that conform to engineering specifications. A process capability index uses both the process variability and the process specifications to determine whether a process is "capable". Process capability indices are dimensionless measures that relate the output dispersion of a process allowed by its specification tolerance limits to the actual dispersion of the process. These indices allow the comparison across a whole range of processes, industries, and countries. The potential process capability index $\left(C_{p}\right)$ and process capability index $\left(C_{p k}\right)$ are two common metrics used to measure the process capability (English and Taylor, 1993).

Bag manufacturing industries have strived in recent years to increase their product quality and satisfy customers. Most of the bag producers been forced to cut costs, improve quality and meet the ever-changing needs of an increasingly educated consumers. Polypropylene bag is important for domestic and heavy weight industry products packaging. The raw material (polypropylene) undergoes different processes including extrusion, weaving, laminating, and printing to produce the bag. At all stages, wastes are generated and each production stages are time dependent to each other to produce the final bag. The above points have cause special observation to be carried out on parameters that cause time delay and waste of materials in the production line. Thus, a process capability analysis is carried out to ascertain the performance of the production process. This paper presents a comprehensive investigation and analysis of the process capability of a bag manufacturing company with two production plants.

\section{MATERIALS AND METHODS}

Data Acquisition: The case study organization is a foremost producer of polypropylene bags in Nigeria. 
The company has two plants for production which runs for the twelve months of the year except for shut down due to maintenance or breakdown. The aim is to assess production capability of the two plants (Plants 1 and 2) used in the case study.

For purpose of this study, production data was collected over a period of 9 months. The data collected includes plant production outputs, rework and scrap data from the plants.

Data Analysis: Process Capability: Process Capability refers to the evaluation of how well a process meets specifications or the ability of the process to produce parts that conform to engineering specifications. A process capability index uses both the process variability and the process specifications to determine whether a process is "capable". Process capability indices are dimensionless measures that relate the output dispersion of a process allowed by its specification tolerance limits to the actual dispersion of the process (Erameh et el., 2016). These indices allow the comparison across a whole range of processes, industries, and countries. The potential process capability index $\left(C_{p}\right)$ and process capability index $\left(C_{p k}\right)$ are two common metrics used to measure the process capability (Chen et al,, 2001; English and Taylor, 1993).

The Potential process capability index $(C p)$ is defined as the ratio of specification width over the process spread.

$$
\mathrm{C}_{\mathrm{p}}=\frac{\text { Specification Width }}{\text { Process spread }}=\frac{\text { USL-LSL }}{6 \sigma}
$$

Where USL and LSL are the upper and the lower specification limits and $\sigma$ the in-control standard deviation of the production process.

The specification width is predefined and fixed. It defines the allowable process variation. The process spread is the sole influence on the $\mathrm{Cp}$ index as it describes the actual process variation. The population standard deviation, $\sigma$ is usually estimated by the equations above. When the spread is wide (more variation), the $\mathrm{Cp}$ value is small, indicating a low process capability. When the spread is narrow (less variation), the $\mathrm{Cp}$ value becomes larger, indicating better process capability.

The Process Capability Index $\mathrm{C}_{\mathrm{pk}}$ is a measure of the actual capability of the process. It considers both process variation $(\sigma)$ and the process location or mean $(\overline{\mathrm{X}})$.
In real life, very few processes are at their desirable target. An off-target process should be "penalized" for shifting from where it should be. The $C_{p k}$ is the index for measuring this real capability when the off-target penalty is taken into consideration.

The penalty, or degree of bias, $\mathrm{k}$ is defined as:

$$
\mathrm{k}=\frac{\mid \text { Target }(\mathrm{T})-\text { process Mean }(\mu) \mid}{\frac{1}{2}(\mathrm{USL}-\mathrm{LSL})}
$$

and the process capability index is defined as:

$$
\begin{aligned}
& \mathrm{C}_{\mathrm{pk}}=\mathrm{C}_{\mathrm{p}}(1-\mathrm{k}) \\
& \mathrm{C}_{\mathrm{pk}}=(1-\mathrm{k}) \frac{\mathrm{USL}-\mathrm{LSL}}{6 \sigma}
\end{aligned}
$$

When the process is perfectly on target, $\mathrm{k}=0$ and $C_{p k}$ $=C_{p}$.

Note that $C_{p k}$ index increases as both of the following conditions are satisfied.

- The process is as close to the target as possible ( $\mathrm{k}$ is small).

- The process spread is as small as possible (process variation is small).

The cases above deal with when there are two specification limits, USL and LSL. However, when there is a one-sided specification limit, or when the target is not specified, $C_{p k}$ may be more conveniently calculated as:

$\mathrm{C}_{\mathrm{pk}}=\frac{\mid \text { Process Mean }(\mu)-\text { closer specification limit from } \mu \mid}{3 \sigma}$

We often use upper capability index (CPU) and lower capability index (CPL).

- $\quad$ CPU is the upper tolerance spread divided by the actual upper process spread.

- $\quad$ CPL is defined as the lower tolerance spread divided by the actual lower process spread.

$$
\mathrm{C}_{\mathrm{pk}}=\min \left[\frac{\overline{\mathrm{X}}-\mathrm{LSL}}{3 \sigma}, \frac{\mathrm{USL}-\overline{\mathrm{X}}}{3 \sigma}\right]
$$

$C_{p k}$ may be defined as the minimum of CPU or CPL. It relates the scaled distance between the process mean and the closest specification limit to half the total process spread.

For a process to be capable, $C_{p}$ and $\mathrm{C}_{\mathrm{pk}}$ must be greater or equal to 1 with larger indicating better 
capability. If $C_{p} \neq C_{p k}$ then the process is not centered.

Other capability indices are Pp, PPL, PPU, Ppk, and

$$
\mathrm{C}_{\mathrm{pm}}=\frac{\mathrm{USl}-\mathrm{LSL}}{6 \sqrt{\left(\sigma^{2}+\left(\mu_{0}-\mathrm{T}\right)^{2}\right)}}
$$

are also calculated and reported (Lupo, 2015).

Shi et al., (2016) describe the capability indices for a case of a non-normal distribution as:

$$
\begin{gathered}
\mathrm{C}_{\mathrm{p}(\mathrm{p})}=\frac{\mathrm{USL}-\mathrm{LSL}}{\mathrm{P}_{99.865}-\mathrm{P}_{0.135}} \\
\mathrm{C}_{\mathrm{pk}(\mathrm{p})}=\min \left[\frac{\mathrm{m}-\mathrm{LSL}}{m-P_{0.135}}, \frac{\mathrm{USL}-\mathrm{m}}{P_{99.865}-m}\right]
\end{gathered}
$$

Where $P_{\alpha}$ stands for the $\alpha$ percentile of the fitting distribution and $m$ is the median value of the process. Using yield-based indices,

$$
\begin{gathered}
\mathrm{C}_{\mathrm{p}(\mathrm{y})}=\frac{0.5 \Phi^{-1}(1+\mathrm{F}[\mathrm{USL}-\mathrm{LSL}])}{3} \\
\mathrm{C}_{\mathrm{pk}(\mathrm{y})}=\min \left[\frac{\Phi^{-1}(1-\mathrm{F}(\mathrm{LSL})}{3}, \frac{\Phi^{-1} \mathrm{~F}(\mathrm{USL})}{3}\right]
\end{gathered}
$$

Where $\Phi$ is the continuous density Function of the standard normal distribution while $\mathrm{F}$ is the continuous density function of the F-distribution

Statistical Tests: Test for Significance: A MannWhitney test for significance was carried out on the outputs of the two plants to examine the similarity in production output. A correlation of the two production output data was done to ascertain any relationship between them. A general analysis of both plants was also carried out vis-a-vis output against target. Normal process capability indices and charts such as the capability histogram, capability plot and normal probability plot were drawn.

The Mann-Whitney test of the equality of the medians of the two population is a test performed on the data of the output of both Plants 1 and 2. The purpose of the test is to determine whether the difference between these two outputs is statistically significant and to calculate the corresponding point estimate and confidence interval.

The hypotheses are:

$\mathrm{H}_{0}: h_{1}=h_{2}$ There is no difference between the population medians

$\mathrm{H}_{1}: h_{1} \neq h_{2}$ There is a difference between the population medians

Where $\mathrm{h}$ is the population median.

Test for Relationship: Correlation: Correlation is a test of relationship between two data set. For this analysis, correlation is carried out to determine the level of relationship between the outputs of the two plants involved in production at the company.

Analysis of Plant Ouputs: This section discusses the analysis of the process capability of each production plant in the company. Figure 1 is a graph of the output from Plant 1 and the expected target for the plant over a period of nine months. A general analysis of the output from Plant 1 in the months of observation and data collection shows that production from the plant did not meet the stated target of 600,000 metres in April and May.

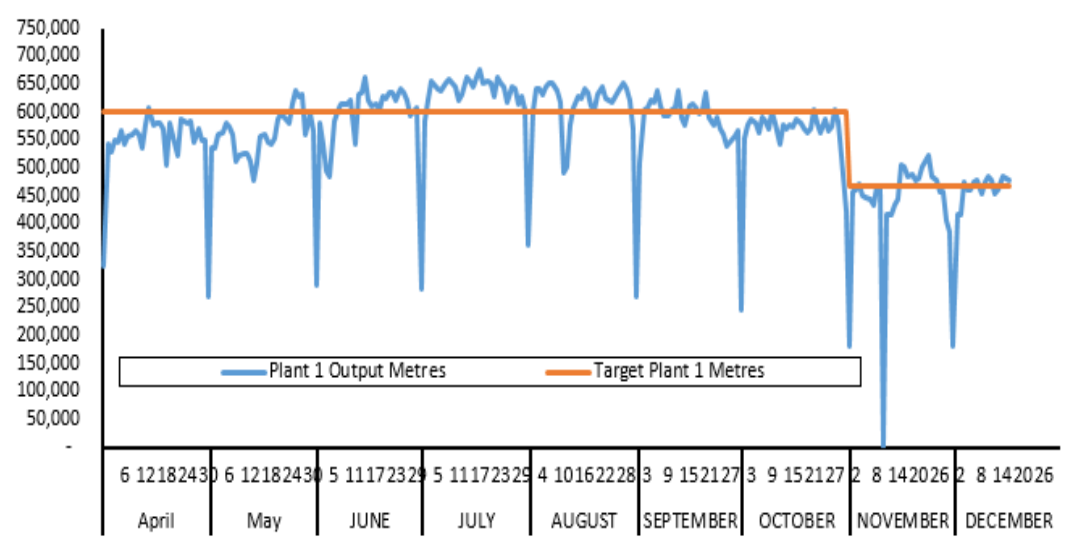

Fig 1: Plant 1 Output against Target

Average production in April and May was 553,023 and 552,037 metres respectively. Production in June, July, August and part of September exceeded expectation as average production peaked in July and August at 630028, and 609,829 respectively. The upsurge in production is attributed to the increase in 
demand, stability of production, and various economic factors. In October, production fell sharply below target as average output from plant 1 stood at 559,944 metres. Figure 2 is a graph of the output from Plant 2 and the expected target for the plant over a period of nine months. In Plant 2, average production did not meet the stated target of 600,000 metres in April, May, and June with average output of $479933,473,150$, and 488,136 metres respectively. Production in July surged (average production of 551, 968 metres) and dipped for the remaining part of the period under study. Average production did not meet the stated target of 550,000 metres for the plant

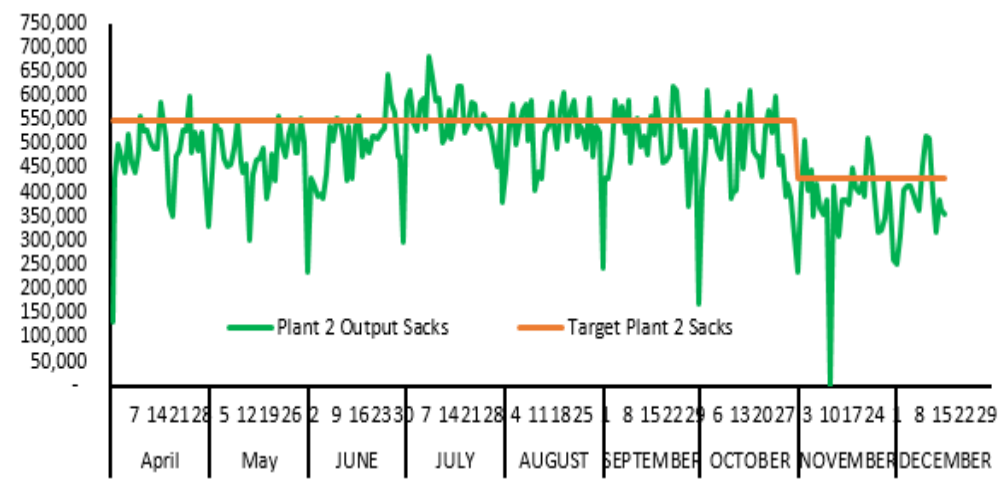

Fig 2: Plant 2 Output against Target

On Plant 1 Output: As shown in Figure 3, the output for the Plant was observed from April to December totaling 261 days. The daily output for the Plant is compared to the target for each day. The mean output from Plant 1 is 557456 metres of sack compared to the target of both 600000 and 469000 metres of sack.
High Variance: The process capability analysis shows that there is a very high variance between the actual and target output of Plant 1.

Skewness: It is also noted that the output from plant 1 is negatively skewed

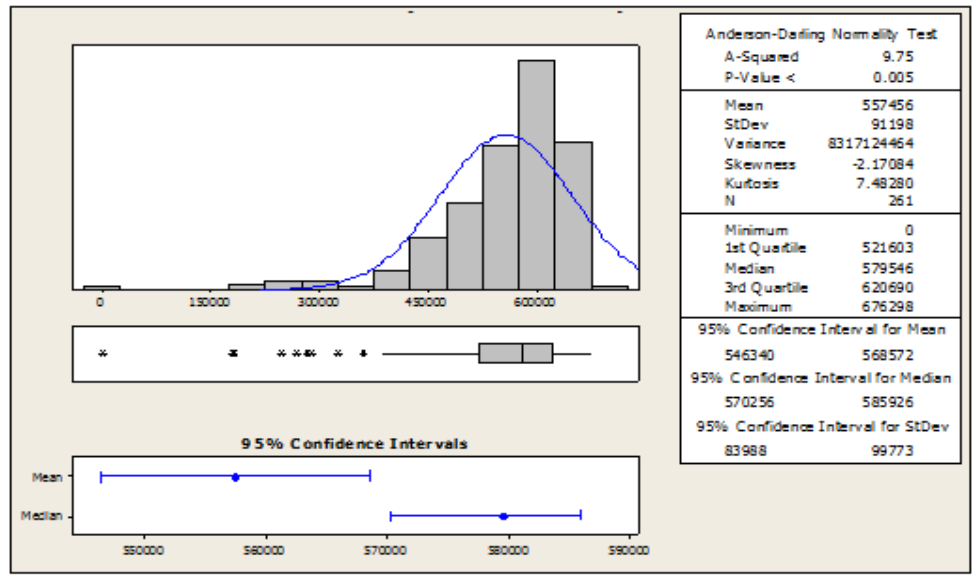

Fig 3: Summary of Plant 1 Output

Result of Correlation Test: A correlation of 0.815 was returned when the tow output data were subjected to Pearson Correlation test. The result indicated that there is a very strong relationship between the outputs of the two plants and further deductions can be made from their data.

\begin{tabular}{cll} 
Result of Test of Significance of difference of Medians \\
\hline & N & Median (ETA) \\
\hline Plant 1 Output & 261 & 579546 \\
Plant 2 Output & 261 & 492500 \\
\hline
\end{tabular}

- $\quad$ Point estimate for ETA1-ETA2 is 81995.

- Confidence Interval: $95 \%$ for ETA1-ETA2 is $(68673,94796)$

- $\quad \mathrm{W}=86943.5$

- $\quad$ Test of ETA1 = ETA2 vs ETA1 not = ETA2 is significant at 0.0000

Interpreting the results: Minitab 21 was used to calculate the sample medians of the ordered data as 69.5 and 78 . The $95.1 \%$ confidence interval for the 
difference in population medians (ETA1-ETA2) is (68673, 94796). The test statistic $\mathrm{W}=86943.5$ has a p-value of 0 when adjusted for ties. Since the p-value is not less than the chosen a level of 0.05 , it can be concluded that there is insufficient evidence to reject $\mathrm{H}_{0}$. Therefore, the data does not support the hypothesis that there is a difference between the population medians.

Plant 1: Capability Report: The Capability Histogram: The process output for Plant 1 (over the study period) appears to be fairly centered between the specification limits. However, the output spread is larger than the specification spread which implies poor capability. There are non-conforming parts below the Lower Specification Limit (LSL: 500,000 metres) and above the Upper Specification Limit (USL: 600,000 metres).

Normal Probability Plot: A normal probability plot displays each data point versus the percentage of values in the sample that are less than or equal to that data point. The plot assesses that ability of the plant to follow a normal distribution. Given that the p-value is less than 0.005 , then the output is not normal. The Anderson-Darling test statistic gives a value of 9.747. Capability Plot: The capability plot consists of three intervals.

- The within interval which represents the potential output tolerance and is given by the subgroup standard deviation. Given that the standard deviation is relatively high (34323), $C_{p}=$ 0.49 and $C_{p k}=0.41$

- The overall interval represents the actual output tolerance and is calculated by six times the overall standard deviation.

- The specification interval represents the interval between the lower and upper specification limits (LSL and USL).

Interpretation: Since the overall output spread is greater than the specification interval spread, then the output requires great improvement.

Given that the output centre (middle mark) in the specification and overall interval are vertically aligned, then the output from plant 1 is process centered. Figure 4 shows the process capability of the output of Plant 1.

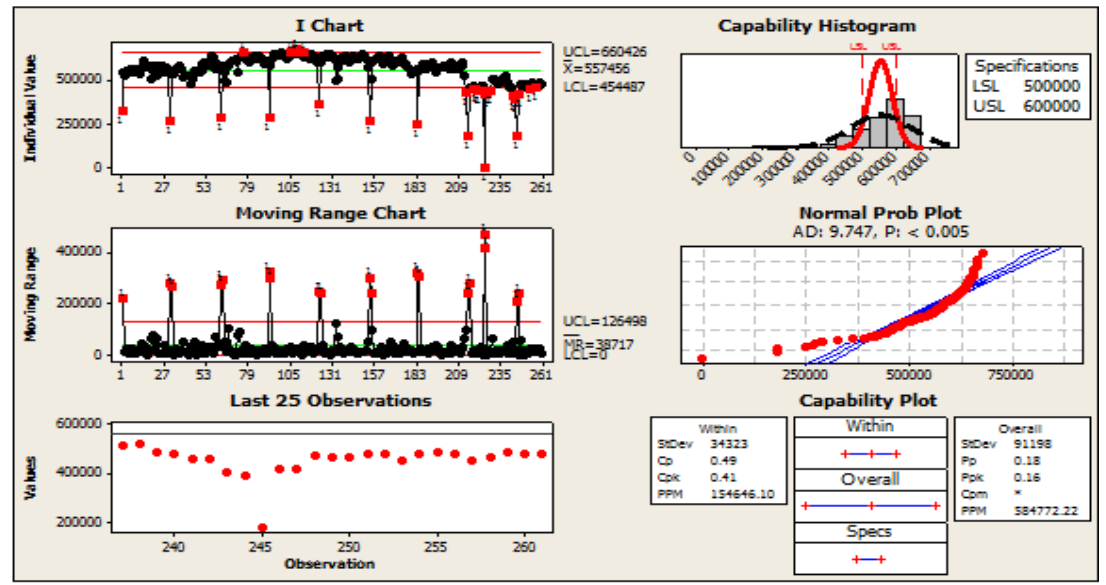

Fig 4: Process Capability Report of Plant 1

Plant 2: Capability Report: The Capability Histogram: The process output for Plant 2 (over the study period) appears to be fairly centered between the specification limits. However, the output spread is larger than the specification spread which implies poor capability. There are non-conforming parts below the Lower Specification Limit (LSL: 430,000 metres) and above the Upper Specification Limit (USL: 550,000 metres).

Normal Probability Plot: The plot assesses that ability of the plant to follow a normal distribution. As the pvalue is less than 0.005 , then the output is not normal. The Anderson-Darling test statistic gives a value of 2.989 .
Capability Plot: The within interval shows that the standard deviation is relatively high (55882), $C_{p}=$ 0.36 and $C_{p k}=0.29, \mathrm{PPM}=293964.53$

- The overall interval represents the actual output tolerance and is calculated by six times the overall standard deviation. $P p=0.22, P p k=0.17$

- The specification interval represents the interval between the lower and upper specification limits (LSL and USL).

Interpretation: Since the overall output spread is greater than the specification interval spread, then the output requires great improvement.

- $\quad$ Given that the output Centre (middle mark) in the specification and overall interval are vertically 
aligned, then the output from plant 2 is process centered.

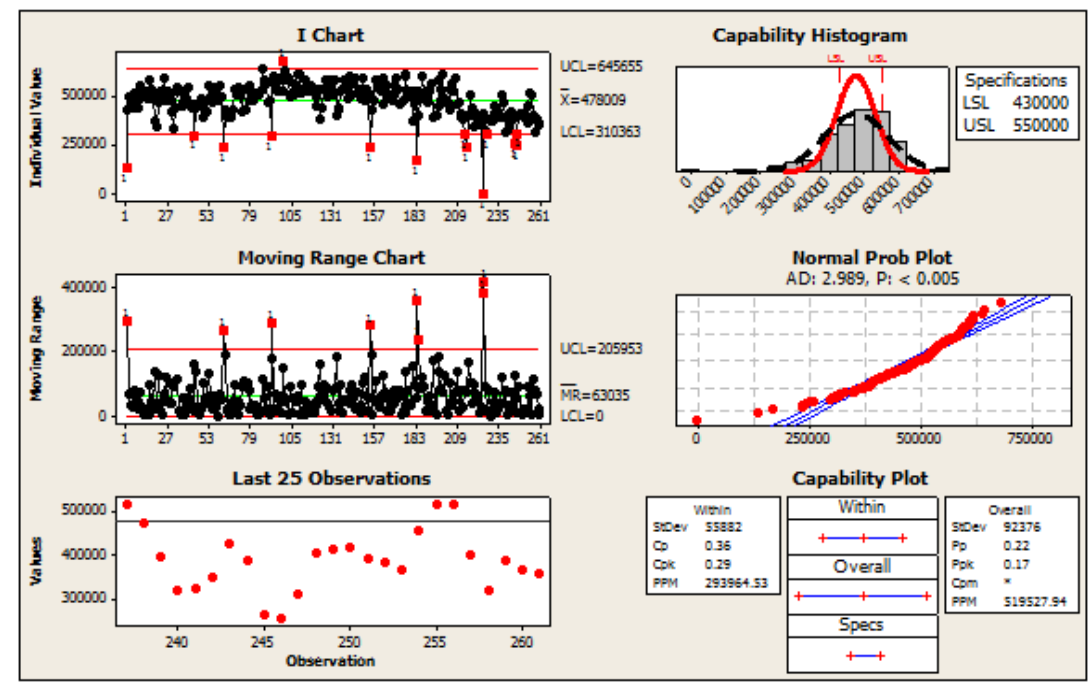

Fig 5: Process Capability for Plant 2

Conclusion: The emphasis of this work has been on process capability and how it aids quality and process improvement. The case study is a manufacturing company that produces polypropylene nylon bags. The outputs of the two Plants (plant 1 and 2) in the company were examined for capability. In plant 1 , it was observed that the overall output spread is greater than the specification interval spread, and that the output requires improvement. Also, the output centre (middle mark) in the specification and overall interval are vertically aligned, thus specifying that the output from plant 1 is process centered. The capability plot of plant 2 shows that the overall output spread is greater than the specification interval spread. Also, the output centre in the specification and overall interval are vertically aligned, thus specifying that the output from plant 2 is also process centered. Due to the peculiarity of the case study organization and corporate governance structure, the proposed improvements could not be implemented as it would disrupt the production process. In line with standard practices worldwide, the following are recommendations that must be put in place to improve the quality of outputs obtainable in the production line.

\section{REFERENCES}

Cao, BY, Xie, XJ. (Eds.). (2012). Fuzzy engineering and operations research. Berlin: Springer. www.springerlink.com

Chen, KS, Huang, ML, Li, RK. (2001). Process capability analysis for an entire product. Inter. J. Prod. Res. 39(17), 4077-4087.
Dharmasena, LS. Zeephongsekul, P. (2016). A new process capability index for multiple quality characteristics based on principal components Inter. J. Prod. Res. 54(15), 4617-4633.

English, JR., Taylor, GD. (1993). Process capability analysis - a robustness study. Inter. J. Prod. Res. 31(7), 1621-1635

Erameh, AA, Raji, NA., Durojaye, RO., Yussouff, AA. (2016). Process capability analysis of a centre lathe turning process. Engineer.8 (03), 79.

Lupo, T. (2015). Fuzzy ServPerf model combined with ELECTRE III to comparatively evaluate service quality of international airports in Sicily. J. Air Transport Manage. 42, 249-259.

Shi, L., Ma, H., Lin, DK. (2016). Process capability analysis via continuous ranked probability score. Qua. Rel. Eng. Inter. 32(8), 2823-2834.

Wooluru, Y., Swamy, DR., Nagesh, P. (2014). The Process Capability Analysis - A tool for process performance measures and metrics - A Case Study. Inter. J. Prod. Res. 8(3), 399-416, ISSN 1800-6450, 399.

Young-Vazquez, D., Becerra, RMB, Carrum-Siller, E., Sánchez-Ramírez, C., Hernández-Hernández, A. (2021). Multi-process Assessment Considering the Error of Measurement Systems Within the Process Capacity Indices. In Techniques, Tools and Methodologies Applied to Quality Assurance in Manufacturing (pp. 175-201). Springer, Cham. 